\title{
Pengembangan modul biologi berbasis penelitian fitoplankton di waduk mulur sukoharjo
}

\author{
Ulin Nuha Latifaa,1,* \\ a Program Studi Pendidikan Biologi, Universitas Veteran Bangun Nusantara, Sukoharjo, Indonesia \\ 1 ulinnlatifa.258@gmail.com* \\ * Corresponding Author
}

\begin{abstract}
ABSTRAK
Tujuan penelitian ini adalah untuk mengetahui jenis-jenis fitoplankton air tawar di Waduk Mulur Kabupaten Sukoharjo yang dapat digunakan sebagai bahan ajar pembuatan sumber belajar modul biologi. Metode yang digunakan dalam penelitian ini adalah metode purposive random sampling. Pengumpulan data dilakukan sebanyak 3 kali pada pagi, siang dan sore hari dengan menggunakan jaring plankton. Modul yang digunakan adalah model penelitian dan pengembangan (R\&D) yang dimodifikasi menjadi 7 langkah: 1) penelitian dan pengumpulan informasi; 2) perencanaan; 3) pengembangan produk awal; 4) uji coba produk awal; 5) revisi produk awal 6) uji lapangan terbatas; 7) revisi produk kedua. Hasil dan kesimpulan spesies fitoplankton yang ditemukan di waduk Mulur Sukoharjo berjumlah 15 spesies dengan indeks keanekaragaman 2,39 (sedang). Penilaian ahli materi, ahli media, guru biologi, dan pengguna modul menyatakan bahwa modul termasuk dalam kategori layak dengan kualifikasi sangat baik dan dapat diterapkan dalam proses pembelajaran sesuai dengan kompetensi dasar yang telah tertulis pada silabus
\end{abstract}

\section{Development of a biology module pased on phytoplankton research in the Mulur Reservoir, Sukoharjo}

The purpose of this study is to determine the types of freshwater phytoplankton in the Mulur Reservoir, Sukoharjo Regency which can be used as materials for making learning resources for biology modules. The research used purposive random sampling method. Data collection was carried out 3 times in the morning, afternoon and evening byused the plankton net. The module usedresearch and development (R\&D) model which modified into 7 steps: 1) research and information gathering; 2) planning; 3) initial product development; 4) initial product trials; 5) initial product revision 6) limited field test; 7) second product revision. The results and conclusions of the phytoplankton species which have been found in the Mulur Sukoharjo reservoir were 15 species with a diversity index of 2.39 (moderate). The assessment of material experts, media experts, biology teacher, and module users representthat the module is proper category with very good qualifications and can be applied in the learning process according to the basic competencies that have been written on the syllabus.
KATAKUNCI

Fitoplankton Air Tawar, Identifikasi,

Modul Biologi

\section{KEYWORDS}

\section{Freshwater}

Phytoplankton, Identification, Biology Module,

This is an openaccess article under the CC-BY-SA license

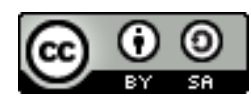

\section{Pendahuluan}

Pembelajaran Biologi pada kurikulum 2013 menuntut aktivitas siswa untuk lebih mandiri serta berpikir kritis terhadap materi yang akan dipelajari. Pembelajaran tersebut dapat melibatkan berbagai komponen ekosistem bahkan memanfaatkan lingkungan sekitar yang ada agar siswa dapat lebih kritis dan tanggap dengan fenomena-fenomena serta keadaan lingkungan sekitar. Ekosistem memiliki hubungan yang erat dengan kehidupan manusia, baik ekosistem daratan maupun ekosistem perairan.Ekosistem perairan daratan terbagi menjadi dua jenis yaitu perairan lontik (mengalir) seperti sungai dan kali, dan perairan lentik (menggenang) seperti waduk, danau, dan bendungan. 
Waduk Mulur terletak di Kabupaten Sukoharjo memiliki fungsi umum sebagai pengairan persawahan masyarakat, selainfungsi tersebut waduk juga dimanfaatkan oleh masyarakat untuk wisata dan budidaya ikan dalam keramba. Salah satu jenis organisme air yang dapat ditemukan di perairan wadukyaitu fitoplankton. Fitoplankton disebut juga sebagai alga, memiliki ukuran yang mikroskopis, hidup secara soliter, atau berkoloni, serta biasa ditemukan melayang-layang di permukaan air (Andriani, Damar, Rahardjo, Charles P. H. Simanjuntak, Aries, \& Reiza, 2017).

Bahan ajar merupakan sumber belajar yang digunakan dalam pembelajaran untuk mencapai suatu tujuan pembelajaran yang mengandung informasi yang digunakan sebagai sarana bagi peserta didik untuk melakukan proses perubahan tingkah laku baik dari lingkungan, tempat maupun seseorang (Majid, 2008). Bahan ajar dapat berbentuk tertulis maupun tidak tertulis seperti handout, buku, modul, brosur, foto, video maupun gambar. Bahan ajar berbasis jigsaw juga dapat digunakan. Bahan ajar yang dicetak dapat dijadikan buku teks, dimana buku teks merupakan sumber belajar yang dibutuhkan di dalam proses perkuliahan (Bahraeni, 2017; Sinambela \& Sinaga, 2020). Modul merupakan bentuk bahan ajar tertulis yang berperan penting dalam kelangsungan belajar yang bersifat praktis dan mudah dipahami secara mandiri oleh peserta didik (D. D. Swastika, 2019). Menurut (Depdiknas, 2008) modul adalah alat atau sarana pembelajaran berisi materi, metode, Batasan dan evaluasi pembelajaran yang dirancang secara sistematik dan menarik untuk mencapai kompetensi pembelajaran.

Penelitian terkait pengembangan modul telah dilakukan oleh beberapa peneliti di antaranya oleh (Utami, 2012) tentang penelitian berjudul pengembangan modul keanekaragaman hayati fitoplankton di sungai gua Pindul Gunung Kidul dan menunjukkan hasil kategori layak. Pengembangan modul materi ekosistem berbasis kearifan lokal di kawasan Goa Kreo oleh (Lestari, 2017) termasuk kategori layak. Penelitian yang telah dilakukan tersebut belum mengarah pada penelitian yang digunakan sebagai bahan modul. Berdasarkan hasil-hasil penelitian sebelumnya maka peneliti bermaksud untuk mengembangkan modul biologi yang berbasis hasil penelitian. Pengembangan modul berbasis penelitian ini berfokus pada penemuan hasil identifikasi fitoplankton di waduk Mulur Sukoharjo. Alasan pemilihan lokasi di waduk Mulur, karena belum pernah ada penelitian tentang fitoplankton (alga) yang digunakan sebagai sumber belajar biologi. Modul alga air tawar (fitoplankton) yang dikembangkan berisi pokok bahasan tentang fitoplankton (alga) air tawar pada materi protista. Materi dalam modul ini berisi pengertian, ciri-ciri, klasifikasi, manfaat, dan identifikasi alga (fitoplankton) hasil penelitian di waduk Mulur Sukoharjo. Modul ini disusun secara menarik dan berisi latihan-latihan soal yang cukup baik untuk mengasah kemampuan berpikir siswa dengan baik.

\section{Metode}

Jenis penelitian ini adalah penelitian dan pengembangan $(R \& D)$ dari Borg and Gall yang telah dimodifikasi menjadi 7 langkah (Nugroho \& Subiyantoro, 2017) yaitu penelitian dan pengumpulan informasi, perencanaan, pengembangan produk awal, uji coba produk awal, revisi produk awal, uji lapangan terbatas, dan revisi produk kedua. Prosedur pengembangan dapat dilihat pada Gambar 1.

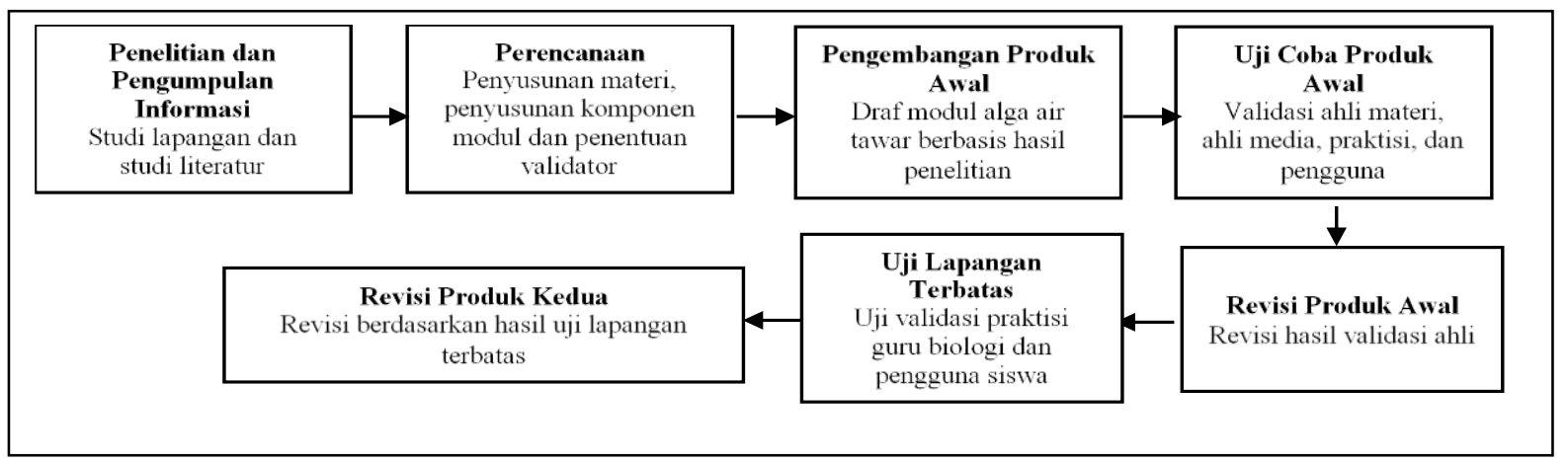

Gambar 1. Prosedur Pengembangan Modul 
Penentuan stasiun penelitian ini menggunakan metode purposive random samping. Titik lokasi penelitian berada di tepi waduk, tepi agak ke tengah waduk, dan tengah waduk. Penelitian dilakukan pada bulan Agustus-September 2020 di Waduk Mulur Sukoharjo untuk lokasi pengambilan sampel dan di Laboratorium Universitas Veteran Bangun Nusantara Sukoharjo untuk pengamatan sampel penelitian.Alat yang digunakan selama penelitian adalah plankton net no 25, botol plankton, mikroskop XSP-13A dengan perbesaran 200x, desk glass, cover glass, pipet, buku catatan, buku referensi fitoplankton danau-danau di pulau jawa (LIPI). Subjek penelitian ini adalah alga air tawar (fitoplankton) di waduk Mulur Sukoharjo. Produk yang dikembangkan berupa modul alga air tawar (fitoplankton) berbasis hasil identifikasi di waduk Mulur Sukoharjo yang praktis dan valid. Data dan sumber data diperoleh dari kegiatan penelitian dan hasil uji validasi validator yang kemudian dianalisis secara deskriptif kualitatif dan deskriptif kuantitatif. Data penilaian para ahli terhadap modul menggunakan skala likert dan dianalisis dengan teknik deskriptif presentase (Sugiyono, 2015) dengan rumus.

$$
p=\frac{\Sigma n_{x}}{\Sigma n_{y}} 100 \%
$$

Penjelasan rumus tersebut adalah $\mathrm{p}$ merupakan presentase nilai keseluruhan, $\mathrm{n}$ banyaknya aspek yang dinilai, sedangkan $\mathrm{x}$ adalah jumlah skor seluruh aspek, dan y adalah jumlah skor maksimum. Setelah mendapatkan hasil skor dari perhitungan rumus maka skor disesuaikan dengan tabel 1 berikut.

Tabel 1. Kriteria Tingkat Kelayakan Modul

\begin{tabular}{ccc}
\hline Skor & Kualifikasi & Keterangan \\
\hline $81 \%-100 \%$ & Sangat Layak & Sangat baik \\
\hline $61 \%-80 \%$ & Layak & Baik \\
\hline $41 \%-60 \%$ & Cukup Layak & Cukup Baik \\
\hline $21 \%-40 \%$ & Kurang Layak & Kurang \\
\hline $0 \%-20 \%$ & Sangat Kurang & Sangat Kurang \\
\hline
\end{tabular}

\section{Hasil dan Pembahasan}

\subsection{Penelitian dan Pengumpulan Informasi}

Tahap penelitian dan pengumpulan informasi ini meliputi studi lapangan dan studi literasi. Studi lapangan dilakukan dengan menganalisis buku ajar/modul yang digunakan di sekolah, serta digunakan juga untuk mengetahui kondisi lapangan penelitian serta potensi alam yang dapat dikembangkan oleh peneliti. Sedangkan studi literatur terdiri dari pengumpulan sumber-sumber bahan ajar, kajian modul pembelajaran yang biasa digunakan, serta informasi-informasi yang digunakan sebagai bahan untuk mengembangkan materi dalam modul.

\subsection{Perencanaan}

Tahap perencanaan dalam penelitian ini meliputi penentuan pokok bahasan, penentukan sistematika isi modul, penentukan validator (ahli media, ahli materi, guru biologi dan siswa), menyusun instrumen validasi, dan menentukan format perangkat pembelajaran. Pokok bahasan dalam modul ini adalah protista sub materi alga air tawar (fitoplankton). Standar kompetensi yang digunakan dalam modul pengembangan ini adalah siswa mampu mengklasifikasikan jenis-jenis protista mirip tumbuhan (alga;fitoplankton) berdasarkan penelitian yang dilakukan. Komponenkomponen modul yang dikembangkan berpedoman pada penulisan modul menurut Depdiknas (2008) yang terdiri dari bagian pembuka (cover modul, redaksi modul, peta konsep, pendahuluan, pretest), bagian inti (tinjauan materi, hasil eksplorasi fitoplankton, rangkuman, tugas mandiri), dan bagian penutup (lembar kegiatan siswa, tes evaluasi, penugasan secara kelompok/portofolio, glosarium, indeks). Selanjutnya penentuan validator yaitu ahli materi, ahli media, praktisi guru biologi, dan pengguna modul.

\subsection{Pengembangan Produk Awal}

Pengembangan produk awal meliputi perancangan draf modul mulai dari halaman sampul (Gambar 2) hingga akhir materi serta penutup, selanjutnya rancangan draf modul disesuaikan 
dengan kaidah penulisan modul. Draf modul yang telah dirancang kemudian dicetak dan selanjutnya akan diuji cobakan untuk mendapatkan penilaian berdasarkan hasil pengembangan.

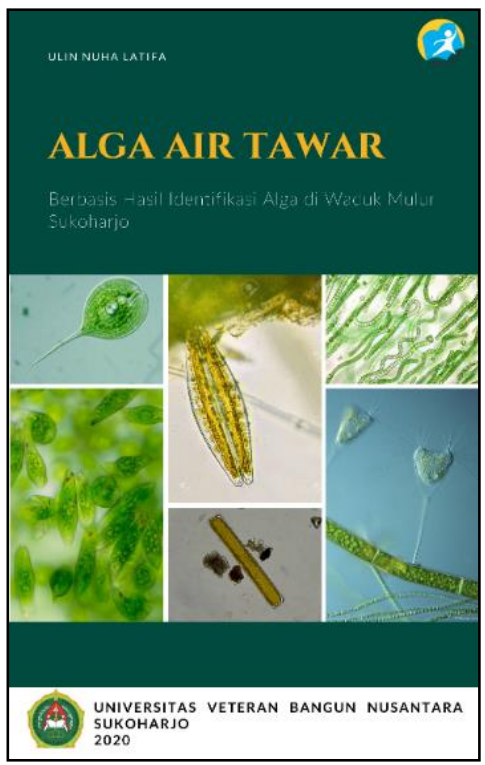

Gambar 2. Sampul buku modul

\subsection{Uji Coba Produk Awal}

Modul yang telah dicetak kemudian diuji cobakan kepada validator ahli yaitu validator ahli materi dan validator ahli media dengan menggunakan kuisioner berupa angket (Haryanti, Septiana, Lestariningsih, \& Lestariningsih, 2020; Rohmiyati, Ashadi, \& Utomo, 2016; Dicka Debby Swastika, 2020). Hasil uji coba produk awal yang telah dilakukan kepada para ahli kemudian mendapatkan masukan serta saran yang digunakan untuk menyempurnakan produk (modul) hasil pengembangan yang kembangkan oleh peneliti. Saran dari ahli materi disajikan pada Tabel 2.

Tabel 2. Saran Ahli Materi

\begin{tabular}{|c|c|}
\hline Saran & Kesimpulan \\
\hline Penyusunan kata pengantar diberi tambahan keunggulan modul berkaitan dengan IT & \multirow{6}{*}{$\begin{array}{l}\text { Layak digunakan dengan } \\
\text { revisi }\end{array}$} \\
\hline Perlu menambahkan keterangan pada peta konsep suapaya lebih mudah dipahami & \\
\hline Gambar asli disandingkan dengan gambar rederensi lain agar lebih jelas & \\
\hline $\begin{array}{l}\text { Memberikan keterangan pada gambar sebagai pembeda antara nama spesies hasil } \\
\text { penelitian dengan hasil referensi. }\end{array}$ & \\
\hline Teliti kembali terkait dengan deskripsi spesies & \\
\hline Penyusunan kata pengantar diberi tambahan keunggulan modul berkaitan dengan IT & \\
\hline
\end{tabular}

Hasil tersebut menunjukkan validasi ahli materi memperoleh kualifikasi layak, sehingga modul yang dikembangkan layak untuk diuji cobakan ke tahap selanjutnya. Saran ahli media dapat dilihat pada Tabel 3 berikut.

Tabel 3. Saran Ahli Media

\begin{tabular}{cc}
\hline Saran & Kesimpulan \\
\hline $\begin{array}{c}\text { Kejelasan gambar yang diberikan kurang jelas sehingga perlu diberi sedikit } \\
\text { pengaturan kontras pada gambar }\end{array}$ & Layak digunakan dengan revisi \\
\hline $\begin{array}{c}\text { Pemilihan warna cover sebaiknya menggunakan gambar atau tampilan yang } \\
\text { lebih menarik sesuai dengan bentuk modul pada umumnya }\end{array}$ & \\
\hline
\end{tabular}

\subsection{Revisi Produk Awal}

Dalam tahap sebelumnya modul hasil pengembangan telah diuji coba kepada ahli materi dan ahli media dan telah mendapatkan hasil yang sangat baik. Selanjutnya dilakukan revisi produk 
awal hasil validasi oleh para ahli. Revisi produk dilakukan atas hasil uji coba produk awal. Revisi oleh ahli materi pada Tabel 4.

Tabel 4, Revisi Ahli Materi

\begin{tabular}{|c|c|}
\hline Aspek Materi & Perbaikan \\
\hline $\begin{array}{c}\text { Penyusunan kata pengantar diberi tambahan } \\
\text { keunggulan modul berkaitan dengan IT }\end{array}$ & $\begin{array}{l}\text { Pada bagian kata pengantar diberi tambahan berupa keunggulan } \\
\text { modul dan berkaitan dengan IT }\end{array}$ \\
\hline $\begin{array}{l}\text { Perlu menambahkan keterangan pada peta } \\
\text { konsep suapaya lebih mudah dipahami }\end{array}$ & Keterangan pada peta konsep sudah ditambahkan \\
\hline $\begin{array}{l}\text { Gambar asli disandingkan dengan gambar } \\
\text { referensi lain agar lebih jelas }\end{array}$ & Gambar asli telah disandingkan dengan gambar referensi \\
\hline $\begin{array}{l}\text { Memberikan keterangan pada gambar sebagai } \\
\text { pembeda antara nama spesies hasil penelitian } \\
\text { dengan hasil referensi. }\end{array}$ & Keterangan pada gambar telah diberi pembeda \\
\hline $\begin{array}{c}\text { Teliti kembali terkait dengan deskripsi } \\
\text { spesies }\end{array}$ & $\begin{array}{l}\text { Deskripsi spesies telah diteliti sehingga sesuai dengan sumber } \\
\text { literatur yang benar }\end{array}$ \\
\hline
\end{tabular}

Sedangkan saran dan masukan dari ahli media dapat dilihat pada Tabel 5.

Tabel 5. Revisi Ahli Media

\begin{tabular}{|c|c|}
\hline Aspek Media & Perbaikan \\
\hline $\begin{array}{l}\text { Kejelasan gambar yang diberikan kurang jelas } \\
\text { sehingga perlu diberi sedikit pengaturan } \\
\text { kontras pada gambar }\end{array}$ & $\begin{array}{l}\text { Gambar telah diperjelas dengan pengaturan kontras dan telah diberi } \\
\text { gambar referensi }\end{array}$ \\
\hline $\begin{array}{c}\text { Ukuran gambar yang disajikan sebaiknya } \\
\text { dibesarkan }\end{array}$ & Ukuran gambar pada modul telah diperbesar \\
\hline $\begin{array}{c}\text { Pemilihan warna cover sebaiknya } \\
\text { menggunakan gambar atau tampilan yang } \\
\text { lebih menarik sesuai dengan bentuk modul } \\
\text { pada umumnya }\end{array}$ & $\begin{array}{l}\text { Tampilan pada cover baik warna maupun gambar telah disesuaikan } \\
\text { sesuai dengan bentuk modul pada umumnya }\end{array}$ \\
\hline
\end{tabular}

Hasil validasi tersebut kemudian dianalisis dan dikonversikan dalam bentuk persentase. Hasil validasi tersebut dapat dilihat pada Tabel 6.

Tabel 6. Hasil Validasi draf Modul oleh validator ahli

\begin{tabular}{ccc}
\hline Validator & Presentase & Kualifikasi \\
\hline Ahli Materi & $86 \%$ & Sangat Baik \\
Ahli Media & $88 \%$ & Sangat Baik \\
\hline
\end{tabular}

\subsection{Uji Lapangan Terbatas}

Uji lapangan terbatas dilakukan untuk mengetahaui kepraktisan modul dengan memberikan form penilaian berupa kuisioner/ angket kepada praktisi guru biologi dan pengguna modul (siswa). Hasil penilaian oleh guru biologi dapat dilihat pada Tabel 7.

Tabel 7. Saran praktisi guru biologi

\begin{tabular}{ccc}
\hline Validator & Saran & Kesimpulan \\
\hline Guru Biologi 1 & $\begin{array}{c}\text { Modulsudah baik, namun perlu } \\
\text { ditambahkan beberapa deskripsi } \\
\text { tentang spesies yang ditemukan }\end{array}$ & Layak, dengan revisi sesuai saran \\
\hline Guru Biologi 2 & Modul sudah bagus dan layak, & Layak, dengan revisi sesuai saran \\
& namun saya sarankan agar & \\
& latihan soal yang diberikan & \\
& lebih banyak lagi & \\
\hline
\end{tabular}

Proses uji lapangan terbatas oleh pengguna modul (siswa) dilakukan terhadap 10 siswa kelas X dengan cara mengisi kuisioner/ angket dan didapatkan hasil berupa saran dari siswa pada Tabel 8 . 
Tabel 8. Saran Pengguna Modul

\begin{tabular}{ccc}
\hline Validator & Saran & Kesimpulan \\
\hline Siswa 1 & $\begin{array}{c}\text { Modul sudah baik, namun pada gambar } \\
\text { spesies ada yang kurang jelas }\end{array}$ & Layak \\
\hline Siswa 2 & $\begin{array}{c}\text { Dalam modul ini materinya sudah bagus } \\
\text { dengan hasil penelitian disajikan dengan baik }\end{array}$ & Layak \\
\hline Siswa 3 & Modul ini sudah lengkap dan materinya \\
mudah dipahami & Layak \\
\hline Siswa 4 & $\begin{array}{c}\text { Soal-soal dalam modul ini sudah baik namun } \\
\text { bisa ditambahkan lagi agar semakin banyak } \\
\text { latihan soal yang diberikan }\end{array}$ & Layak \\
\hline
\end{tabular}

\subsection{Revisi Produk Kedua}

Revisi produk kedua dilakukan berdasarkan saran yang telah diperoleh oleh praktisi guru biologi dan pengguna modul (siswa) pada tahap uji lapangan terbatas. Perbaikan hasil uji lapangan terbatas oleh praktisi guru biologi dapat dilihat pada Tabel 9.

Tabel 9. Revisi Praktisi Guru Biologi

\begin{tabular}{cc}
\hline Saran & Perbaikan \\
\hline $\begin{array}{c}\text { Modul ini sudah baik, namun perlu ditambahkan kembali beberapa } \\
\text { deskripsi tentang spesies yang ditemukan agar lebih jelas untuk } \\
\text { dipahami siswa }\end{array}$ & $\begin{array}{c}\text { Deskripsi setiap spesies telah } \\
\text { ditambahkan }\end{array}$ \\
$\begin{array}{c}\text { Modul ini sudah bagus dan layak, namun saya menyarankan agar } \\
\text { latihan soal yang diberikan lebih banyak lagi supaya siswa } \\
\text { mendapatkan banyak latihan soal terutama soal penalaran }\end{array}$ & $\begin{array}{c}\text { Latihan soal yang ada pada modul telah } \\
\text { ditambahkan }\end{array}$ \\
\hline
\end{tabular}

Setelah dilakukan perbaikan dari hasil uji lapangan terbatas kemudian dilakukan analisis dalam bentuk presentase dan didapatkan hasil pada Tabel 10.

Tabel 10. Hasil Penilaian Praktisi Guru Biologi

\begin{tabular}{ccl}
\hline Guru & Presentase & Kualifikasi \\
\hline Guru Biologi 1 & $85 \%$ & Sangat Baik \\
\hline Guru Biologi 2 & $82 \%$ & Sangat Baik \\
\hline Rata-rata & $84 \%$ & Sangat Baik \\
\hline
\end{tabular}

Hasil revisi produk kedua oleh praktisi guru biologi diperoleh hasil $84 \%$ sehingga termasuk dalam kategori layak dengan kualifikasi sangat baik, hal ini sesuai dengan pendapat menurut (Asyhari \& Silvia, 2016) dan (Aprilia, Lestariningsih, \& Ayatusa'adah, 2020) yang menyatakan bahwa presentase pada rentang angka 81-100 termasuk kategori layak dengan kualifikasi sangat baik. Penilaian yang dilakukan oleh pengguna modul (siswa) pada tahap revisi produk kedua dapat dijelaskan pada Tabel 11.

Tabel 11. Saran dari siswa

\begin{tabular}{cc}
\hline Saran & Perbaikan \\
\hline $\begin{array}{c}\text { Modul sudah baik, namun pada gambar spesies } \\
\text { ada yang kurang jelas }\end{array}$ & $\begin{array}{c}\text { Gambar spesies pada modul telah diperbaiki sehingga } \\
\text { terlihat cukup jelas }\end{array}$ \\
\hline $\begin{array}{c}\text { Soal-soal dalam modul ini sudah baik namun bisa } \\
\text { ditambahkan lagi agar semakin banyak latihan } \\
\text { soal yang diberikan }\end{array}$ & Soal latihan sudah ditambahkan \\
\hline
\end{tabular}

Setelah dilakukan perbaikan berdasarkan saran pengguna modul kemudian dilakukan analisis dan diperoleh hasil $86 \%$ dengan kualifikasi sangat baik. Hasil penilaian dapat dilihat pada Tabel 12. 
Tabel 12. Hasil Penilaian Siswa

\begin{tabular}{ccc}
\hline Validator & Presentase & Kualifikasi \\
\hline Siswa 1 & $79 \%$ & Baik \\
Siswa 2 & $83 \%$ & Sangat Baik \\
Siswa 3 & $79 \%$ & Baik \\
Siswa 4 & $94 \%$ & Sangat Baik \\
Siswa 5 & $90 \%$ & Sangat Baik \\
Siswa 6 & $92 \%$ & Sangat Baik \\
Siswa 7 & $93 \%$ & Sangat Baik \\
Siswa 8 & $83 \%$ & Sangat Baik \\
Siswa 9 & $81 \%$ & Sangat Baik \\
Siswa 10 & $87 \%$ & Sangat Baik \\
\hline Rata-rata & $86 \%$ & Sangat Baik
\end{tabular}

Secara keseluruhan rata-rata hasil penilaian modul biologi hasil pengembangan ini menunjukkan kategori layak dengan kualifikasi sangat baik. Sehingga modul hasil pengembangan ini dapat digunakan sebagai bahan ajar bagi siswa kelas X SMA. Penelitian Fitoplangton di waduk Mulur sesuai dengan hasil penelitian lain menyatakan sumber belajar dengan pemanfaatan lingkungan sekitar dapat memudahkan siswa untuk memahami materi karena siswa mengalami secara langsung interaksi dengan objek yang dipelajarinya (Irwandi \& Fajeriadi, 2020). Sumber belajar dengan pemanfaatan lingkungan berisi aktivitas pengamatan langsung terhadap obyek dan fenomena biologi, sehingga lebih menarik dan menyenangkan (Khanifah, Pukan, \& Sukaesih, 2012). Sumber belajar dapat memudahkan proses pembelajaran, memiliki daya tarik, dan mampu memotivasi siswa untuk lebih aktif, lebih interaktif, dan lebih kritis (Suwarni, 2015).

\section{Kesimpulan}

Kesimpulan dari penelitian ini adalah pengembangan modul biologi fitoplankton air tawar berbasis hasil identifikasi di waduk Mulur Sukoharjo telah dinilai kelayakannya melalui validasi ahli materi, ahli media, praktisi guru biologi, dan pengguna siswa. Hasil penilaian oleh ahli materi menunjukkan hasil 86\% (sangat valid), penilaian ahli media 88\%, penilaian rata-rata oleh praktisi guru biologi $84 \%$ (sangat valid) dan rata-rata penilaian oleh pengguna modul $86 \%$. Sehingga modul biologi yang dikembangkan layak untuk diterapkan dalam proses pembelajaran. Saran dari penelitian ini diantaranya diharapkan modul yang dikembangkan dapat dijadikan sebagai salah satu bahan ajar atau pedoman yang digunakan guru untuk membantu siswa dalam menggali potensi alam sekitar, serta saran untuk penelitian selanjutnya disarankan untuk lebih mengembangkan kembali potensi alam yang ada di lingkungan sekitar agar dapat dimanfaatkan khususnya dalam ilmu pengetahuan.

\section{Ucapan Terimakasih}

Peneliti mengucapkan terimakasih kepada para dosen, validator ahli, praktisi guru biologi serta siswa yang telah berpartisipasi dan membantu, memberikan saran, serta mendukung dalam pelaksanaan penelitian serta pengembangan yang telah dilakukan oleh peneliti hingga terselesaikannya penelitian ini.

\section{Referensi}

Andriani, A., Damar, A., Rahardjo, M., Charles P. H. Simanjuntak, Aries, A., \& Reiza, M. A. (2017). KELIMPAHAN FITOPLANKTON DAN PERANNYA Abundance of Phytoplankton and its Role as Fish Food Sources in Pabean Bay ,. Jurnal Sumberdaya Akuatik Indopasifik, 1(2), 133-144.

Aprilia, L., Lestariningsih, N., \& Ayatusa'adah. (2020). Pengembangan Penuntun Praktikum Berbasis Inkuiri Terbimbing Materi Interaksi Makhluk Hidup pada Siswa MTs Darul Amin Palangka Raya Lidia. Journal of Biology Learning, 2(2), 112-120. 
Asyhari, A., \& Silvia, H. (2016). Pengembangan Media Pembelajaran Berupa Buletin dalam Bentuk Buku Saku untuk Pembelajran IPA Terpadu. Jurnal Ilmiah Pendidikan Fisika AlBiruni, 5(1), 1. https://doi.org/10.24042/jpifalbiruni.v5i1.100

Bahraeni, B. (2017). EFEKTIFITAS PENGEMBANGAN BAHAN AJAR ILMU PENDIDIKAN ISLAM BERBASIS MODEL PEMBELAJARAN KOOPERATIF TIPE JIGSAW MELALUI KEGIATAN DESIMINASI PADA STAIS DDI MAROS. Inspiratif Pendidikan, 6(1), 100. https://doi.org/10.24252/ip.v6i1.4920

Depdiknas. (2008). Penulisan modul. Jakarta: Direktorat Jenderal Peningkatan Mutu Pendidik Dan Tenaga Kependidikan.

Haryanti, D., Septiana, N., Lestariningsih, N., \& Lestariningsih, N. (2020). Pengembangan Modul Terintegrasi Keislaman Materi Sistem Reproduksi Kelas IX SMPN 4 Katingan Kuala. Journal of Biology Learning, 2(1), 33-40. https://doi.org/10.32585/.v2i1.561

Irwandi, I., \& Fajeriadi, H. (2020). Pemanfaatan Lingkungan sebagai Sumber Belajar untuk Meningkatkan Minat dan Hasil Belajar Siswa SMA di Kawasan Pesisir, Kalimantan Selatan. BIO-INOVED : Jurnal Biologi-Inovasi Pendidikan, $1(2), \quad 66$. https://doi.org/10.20527/binov.v1i2.7859

Khanifah, S., Pukan, K. K., \& Sukaesih, S. (2012). Pemanfaatan Lingkungan Sekolah Sebagai Sumber Belajar Untuk Meningkatkan Hasil Belajar Siswa. Unnes Journal of Biology Education, 1(1), 66-73. https://doi.org/10.15294/jbe.v1i1.379

Lestari, A. W. (2017). Pengembangan modul pembelajaran biologi berbasis kearifan lokal di Kawasan Wisata Goa Kreo pada materi ekosistem kelas X SMA negeri 16 Semarang. UIN Walisongo.

Majid, A. (2008). Perencanaan Pembelajaran. Bandung: PT Remaja Rosdakarya.

Nugroho, A. A., \& Subiyantoro, S. (2017). Pengembangan Modul Sistematika Tumbuhan Tinggi Berbasis Guided Discovery untuk Mengembangkan Kemampuan Berpikir Kritis Mahasiswa Pendidikan Biologi. Bio-Pedagogi: Jurnal Pembelajaran Biologi, 6(2). Retrieved from https://jurnal.uns.ac.id/pdg/article/view/20696

Rohmiyati, N., Ashadi, A., \& Utomo, S. B. (2016). Pengembangan Modul Kimia Berbasis Inkuiri Terbimbing pada Materi Reaksi Oksidasi-Reduksi The Development of Chemical Modules Based Guided Inquiry in the Oxidation and Reduction Reactions Matter. A, 2 (2), 2016, 223 229 Pen, 2(2), 223-229.

Sinambela, M., \& Sinaga, T. (2020). PENGEMBANGAN BAHAN AJAR BIOLOGI UMUM SEBAGAI SUMBER BELAJAR UNTUK BUKU PEGANGGAN MAHASISWA. Journal of Biology Education, 8(3).

Suwarni, E. (2015). Pengembangan Buku Ajar Berbasis Lokal Materi Keanekaragaman Laba-Laba Di Kota Metro Sebagai Sumber Belajar Alternatif Biologi Untuk Siswa Sma Kelas X. BIOEDUKASI (Jurnal Pendidikan Biologi), 6(2), 86-92. https://doi.org/10.24127/bioedukasi.v6i2.336

Swastika, D. D. (2019). Pengembangan modul pembelajaran terintegrasi keislaman mata kuliah botani tumbuhan tinggi materi angiospermae kelas liliopsida. IAIN Palangka Raya.

Swastika, D. D. (2020). Pengembangan Modul Pembelajaran Terintegrasi Keislaman Mata Kuliah Botani Tumbuhan Tinggi Materi Angiospermae Kelas Liliopsida. Journal of Biology Learning, 2(1), 23-32. https://doi.org/10.32585/.v2i1.560

Utami, R. B. (2012). Penyusunan Modul Keanekaragaman Hayati Berdasarkan Penelitian Keanekaragaman Fitoplankton di Sungai Gua Pindul Gunung Kidul Bagi Siswa Kelas X SMA. Universitas Negeri Yogyakarta., Yogyakarta: 